\title{
O ensino de habilidades motoras esportivas na escola e o esporte de alto rendimento: discurso, realidade e possibilidades
}

CDD. 20.ed. 152.3

796.017

\author{
Go TANI* \\ Luciano BASSO* \\ Sérgio Roberto SILVEIRA** \\ Walter Roberto CORREIA* \\ Umberto Cesar CORREA*
}

\section{Resumo}

A massificação da prática esportiva começando pela escola tem sido sugerida como uma forma eficaz para transformar o Brasil numa potência no esporte de alto rendimento. 0 objetivo deste ensaio é analisar e refletir sobre o discurso, a realidade e as possiblidades de ensino do esporte na escola, tendo como pano de fundo a relação entre a Educação Física Escolar e o esporte de alto rendimento. Em outras palavras, fazer uma análise crítica para qualificar a vinculação escola-esporte de alto rendimento com o intuito de deixar claro o papel social da escola e a sua eventual contribuição para a formação de atletas, e para discutir as possibilidades reais de se ensinar o esporte na escola, particularmente as habilidades motoras, consideradas as condições em que ela se encontra.

Palavras-Chave: Educação física escolar; Esporte; Ensino de habilidades motoras.

\section{Considerações iniciais}

A escolha para sediar dois grandes eventos esportivos nos próximos anos, a Copa do Mundo de Futebol e os Jogos Olímpicos, respectivamente, em 2014 e 2016, criou no Brasil um clima de euforia, de expectativa, mas também de muitas preocupaçóes, com o esporte a ocupar um lugar de destaque na mídia, na política, na economia, enfim, na vida social do país.

Não resta dúvida de que ser escolhido para promover esses megaeventos esportivos constitui, para qualquer país, uma enorme conquista, haja vista o gigantesco esforço, mobilização e investimento que os pretendentes dedicam para obter a honrosa indicação, numa disputa hercúlea que extrapola em muito o domínio esportivo. Não é por menos que os bastidores dessa batalha são ampla e longamente explorados pela mídia, tamanha é a curiosidade e os interesses de diferentes matizes que o assunto envolve e desperta.

No entanto, as motivaçōes e os interesses que levaram o país a se candidatar, assim como os eventuais prós e contras da sua escolha para promover esses dois notáveis eventos esportivos são assuntos ainda em discussão que preocupam a sociedade. Afinal, a iniciativa foi do governo, mas na eventualidade de um fracasso, sobretudo no plano esportivo e econômico, o ônus de sua realização a ela caberá. Para os objetivos do presente ensaio importa destacar que, no plano estritamente esportivo, ao país escolhido fica inerentemente atribuída a pesada responsabilidade de não fazer feio nas competições.

No que concerne aos Jogos Olímpicos, cientes dessa responsabilidade, os países se preparam de antemão desenvolvendo um amplo e arrojado projeto de formação e treinamento de atletas, para fazer com que os resultados desse empreendimento coincidam com a realização do evento. Trata-se de colocar em prática um projeto, cuja meta para ser alcançada exige, no mínimo, um prazo correspondente, em linhas gerais, ao tempo necessário para formar e treinar atletas de alto nível nas diferentes modalidades esportivas. Isto significa que, se para lograr essa meta são necessários, por exemplo, 10 anos de árduo trabalho, o país que não leva em consideração esse prazo corre um sério risco de se sujeitar a um retumbante fracasso em termos esportivos. 
Tudo indica que essa preparação não está sendo feita no Brasil, pelo menos de forma organizada como se requer. Torna-se cada vez mais provável repetir-se em 2016 o mesmo cenário que vem ocorrendo de quatro em quatro anos já há algumas décadas: indignados com o desempenho abaixo das expectativas dos atletas, dirigentes esportivos, ex-atletas, jornalistas esportivos, empresários esportivos, políticos esportivos e outros tantos vêm a público fazer críticas, apresentar possíveis explicações e, mais do que isso, sugerir fórmulas eficazes para o sucesso nas próximas Olimpíadas ${ }^{1}$.

Dentre as fórmulas reiteradamente apresentadas, uma se destaca por ter cadeira cativa na constelação de ideias e sugestôes iluminadas do "day after" olímpico: massificar a prática esportiva começando pela escola ${ }^{1}$. Entenda-se por escola, as aulas de educação física escolar (EFE). Oportuno ressaltar que nas discussões e debates calorosos muito característicos desses momentos pós-evento, essa fórmula para o país se preparar para futuras competições é apresentada de uma maneira que parece não haver discordância em relação a sua eficácia e que as eventuais dificuldades operacionais não são obstáculos significantes para a sua imediata implementação.

Cabe indagar: se o diagnóstico está feito e uma das fórmulas eficientes para solucionar os problemas já é uma velha conhecida, por que a negligência com a preparação? Não é de se estranhar o fato de não se observar no país vencedor da corrida para a realização dos Jogos Olímpicos de 2016 projetos esportivos escolares de abrangência nacional em plena execução? Projetos esses elaborados pelo Ministério da Educação, pelas Secretarias Estaduais e Municipais de Educação e pelas demais entidades educacionais desse país, e iniciados em seu devido tempo, ou seja, há pelo menos sete anos? Afinal se está a apenas três anos do evento. Será que existem problemas com o desenvolvimento de projetos esportivos no interior desses órgãos ou será que se está lidando com duas instituiçôes - escola e esporte de alto rendimento - cujos objetivos são incompatíveis?

Esse cenário remete a um alerta e a um questionamento: o alerta é a necessidade de, do ponto de vista conceitual, fazer-se uma análise crítica para qualificar essa vinculação escola-esporte de alto rendimento e deixar claro o papel social da escola e a sua eventual contribuição para a formação de atletas; o questionamento diz respeito às reais possibilidades, do ponto de vista operacional, de se ensinar o esporte na escola, consideradas as condiçōes em que ela se encontra.

O presente ensaio tem como objetivo aprofundar a reflexão acerca desse alerta e questionamento, pois o que se observa nesse período que antecede o grande evento, em que o país tende a se "embriagar" cada vez mais na atmosfera eufórica da sua realização, é um discurso acrítico de enaltecimento do potencial educacional do esporte de alto rendimento, até mesmo por parte de acadêmicos historicamente contrários ao ensino do esporte na EFE. Além disso, nota-se uma cegueira no que se refere a dura realidade das condiçôes concretas de ensino nas escolas e a ausência de reflexões e, principalmente, de proposiçóes acerca das reais possibilidades de ensino do esporte na escola, devidamente articulados com os objetivos da EFE. Em outras palavras, analisar e refletir sobre o discurso, a realidade e as possiblidades de ensino do esporte na escola, particularmente as habilidades motoras, tendo como pano de fundo a relação entre a EFE e o esporte de alto rendimento, é o que se procura nesse ensaio.

\section{A realidade do ensino do esporte na escola}

O ensino do esporte na escola está amparado legalmente em vários documentos, cujos teores apresentam algumas diferenças dependendo do nível governamental (federal, estadual e municipal) em que se realiza. Não cabe neste momento apresentar e discutir detalhadamente sobre todos eles, mas, para os objetivos do texto julga-se interessante, a partir de alguns exemplos, trazer à discussão duas principais dimensōes do esporte no âmbito escolar para caracterizar a realidade do seu ensino. Trata-se de duas dimensões presentes na Lei de Diretrizes e Bases da Educação Nacional²: a) promoção do esporte educacional e apoio às práticas esportivas não formais; e b) a educação física (EF) como um componente curricular da educação básica.

Como documento de referência nacional, a LDB influenciou e consolidou a elaboração de documentos em níveis governamentais inferiores (estaduais e municipais), integrando as propostas educacionais ao desenvolvimento do esporte no interior das escolas, indicando as aulas de EFE para sua aprendizagem, bem como, os programas diversos destinados à participação de alunos em competições. Um exemplo, em nível estadual de São Paulo, com vistas à primeira 
dimensão (promoção do esporte educacional) tem sido desenvolvida por meio das Atividades Curriculares Desportivas (ACD) e dos Jogos Escolares Estado de São Paulo (JEESP). Os JEESP surgem em 2013, em substituição à Olimpíada Escolar do Estado de São Paulo (OESP, 2011/2012), à Olimpíada Colegial do Estado de São Paulo (OCESP, 2002/2010), ao Campeonato Escolar de Esporte (CEE, 1993/2001), aos Jogos Escolares do Estado de São Paulo (JEESP, 1982/1992) e ao Campeonato Colegial de Esporte do Estado de São Paulo (CCEESP, década de 60/1981).

As ACD, estabelecidas pela Resolução SE 14 de $02 / 02 / 2010^{3}$, têm como pressuposto a importância do esporte escolar para o exercício de relações interpessoais e da cidadania. Especificamente, as aulas dessas atividades apresentam como objetivo a prática, em conformidade com a proposta pedagógica da escola, nas seguintes modalidades esportivas: atletismo, basquetebol, capoeira, damas, futsal, handebol, ginástica artística, ginástica geral, ginástica rítmica, judô, voleibol, tênis de mesa e xadrez. Elas ocorrem em horários diferentes daqueles das aulas curriculares de EF, em no mínimo duas e no máximo três aulas semanais, nas quais os alunos são divididos por categoria, modalidade e gênero.

As escolas, cujas turmas de ACD são de esportes envolvidos nos JEESP, têm o compromisso de participação nos mesmos. Estes, por sua vez, são desenvolvidos conjuntamente pela Secretaria de Estado da Educação, Secretaria de Estado de Esporte, Lazer e Turismo, Secretaria de Estado dos Direitos da Pessoa com Deficiência e a Secretaria de Estado do Desenvolvimento Econômico, Ciência e Tecnologia, e instituídos pelo Decreto n ${ }^{\circ} 58.986$, de 21/03/20134 e com base na Portaria Conjunta G-CEL/CGEB/GSEDPCD/G-SDCET de 22/03/20135. Além de promover a interação entre alunos, as competições visam à aquisição de hábitos saudáveis e ao desenvolvimento de talentos esportivos.

Embora as ACD e os JEESP estejam relacionados a importantes finalidades como, por exemplo, o desenvolvimento de relações interpessoais, o exercício da cidadania e a aquisição de hábitos saudáveis, o foco dos Jogos está na competição esportiva implicando no envolvimento de uma pequena parcela de alunos. Isso pode ser evidenciado, por exemplo, no próprio projeto de criação da ACD (Disponível em <http://cenp.edunet.sp.gov.br/index.htm>) em que tais atividades são propostas para o treinamento de alunos-atletas com vistas à especialização.

Pode-se dizer que a segunda dimensão do esporte no âmbito escolar (conhecida também como esporte da escola), ou seja, o seu ensino nas aulas de EF, é a mais importante em virtude da própria função da escola: a disseminação do conhecimento, na perspectiva da formação para cidadania, da preparação para o mundo do trabalho e do desenvolvimento da personalidade humana. Diferentemente das ACD e dos JEESP, a EFE é um componente curricular obrigatório em todos os anos escolares. Nesse contexto, o esporte é abordado como matéria de ensino, isto é, como conteúdo curricular que possibilite aos alunos a aquisição de competências para lidar "com" e "sobre" ele ao longo de suas vidas. Tais conhecimentos são considerados essenciais para o exercício da cidadania ${ }^{6}$.

Três aspectos relacionados ao ensino do esporte na EFE são importantes para a compreensão da sua realidade: a) as características e a quantidade de alunos; b) a organização curricular; e c) a infraestrutura escolar. Com respeito aos alunos, deve-se considerar que aqueles alunos-atletas participantes das ACD e dos JEESP supracitados continuam com a obrigatoriedade de participação nas aulas curriculares de EFE, juntamente com os demais alunos de classe. Portanto, as aulas envolvem uma heterogeneidade muito grande de alunos no que se refere a níveis de habilidade, experiências e perspectivas relativas ao esporte. Esse problema fica ainda mais crítico do ponto de vista didático-pedagógico, quando se considera que as aulas se desenvolvem normalmente com 35 a 45 alunos de ambos os gêneros, por sala.

Concernente à organização curricular, embora a EFE seja um componente curricular obrigatório, o seu oferecimento é de apenas duas aulas por semana em todos os níveis de ensino ${ }^{7}$, sendo cada aula de 50 minutos. Isso implica em sérias limitaçōes quanto ao tempo disponível para o ensino do esporte, visto que o mesmo constitui apenas um dos conteúdos de ensino. $\mathrm{O}$ jogo, a ginástica, o exercício e a dança constituem outros componentes da cultura de movimento a serem ensinados nas aulas.

No que tange à infraestrutura, é de amplo conhecimento que, principalmente as escolas públicas localizadas na periferia de diversas cidades, bem como nas zonas rurais, apresentam infraestrutura física precária. Recentemente DUARTE et al. ${ }^{8}$ realizaram um estudo com o objetivo de diagnosticar o estado da infraestrutura das escolas de educação básica da América Latina e sua relação com a aprendizagem (Linguagem e Matemática). Os resultados mostraram precariedade de infraestrutura básica no que se refere à eletricidade, à água, ao saneamento básico e ao telefone, principalmente nas escolas urbanas, 
na maioria dos países, incluindo o Brasil. Verificouse, também, que $35 \%$ das escolas têm espaços inadequados para as aulas de EFE. Os resultados do estudo apontaram para o comprometimento da aprendizagem em razão da infraestrutura precária.

Com relação aos demais Estados brasileiros verificam-se características similares e, dependendo da região, condições ainda mais difíceis para o desenvolvimento de uma EFE de qualidade.

De fato, constataçôes acerca desses três aspectos (características dos alunos, organização curricular e infraestrutura escolar) têm sido evidenciadas em inúmeras pesquisas recentes ${ }^{9-13}$. Em São Paulo, por exemplo, uma pesquisa realizada com 2700 professores de EFE da rede pública estadual de ensino ${ }^{13}$ mostrou que $60 \%$ dos professores de EF tinham problemas de sobrecarga de trabalho, falta de tempo para a preparação do ensino com qualidade, e para envolverem-se em formação continuada, em virtude da quantidade de alunos, aulas e escolas que trabalhavam. Foi observado, também, que uma parcela de professores (4,81\%) não tinha espaço para o desenvolvimento das aulas e que para $42,59 \%$ dos professores o espaço era insuficiente ou inadequado. Também teve destaque nesse estudo, o fato de a falta de material didático estar dentre as principais dificuldades reportadas pela maioria $(87 \%)$ dos professores de EF.
Finalmente, a realidade do ensino do esporte na escola parece estar seriamente comprometida quando se considera as consequências desses três aspectos em interação. Uma delas diz respeito ao tempo limitado de aula ou tempo de prática insuficiente para a ocorrência de aprendizagem. Evidências sobre esse problema também são observadas na literatura científica. Por exemplo, GuEDES e GUEDEs ${ }^{14}$ realizaram uma pesquisa com o objetivo de identificar os tipos de atividade e o nível de intensidade dos esforços físicos dos alunos durante as aulas de EFE. Eles acompanharam 144 aulas envolvendo $5^{\text {as }}, 6^{\text {as }}, 7^{\text {as }} \mathrm{e}$ $8^{\text {as }}$ séries do ensino fundamental e todas as séries do ensino médio de escolas estaduais no município de Londrina. De destaque para o presente tópico, os resultados mostraram que a duração média das aulas foi de 39,7 a 40,4 minutos e que na maior parte desse tempo os alunos ficaram em atividades de transição, ou seja, situações em que os alunos aguardaram o momento de participar das atividades ministradas.

Em síntese, as condiçôes reais de desenvolvimento da EFE colocam em dúvida a própria possibilidade de ensinar o esporte na escola, quanto mais a formação de atletas. Além disso, associadas a essa dificuldade de cariz operacional, existem questōes de ordem conceitual que necessitam ser mais bem refletidas.

\section{A Educação Física Escolar e o esporte}

Apesar de o ensino do esporte na escola estar amparado legalmente em vários documentos, como foi visto, a relação entre a EFE e o esporte tem sido ambígua e até mesmo contraditória ${ }^{15}$ ao longo dos tempos e isto tem ocorrido, fundamentalmente, em virtude da inadequação na concepção de ambos. No que se refere à EFE, essa inadequação emerge de uma visão populista e assistencialista de escola que superestima as suas capacidades reais de realização e, no que concerne ao esporte, de uma visão estreita que o reduz a uma única perspectiva, a de alto rendimento ${ }^{16}$.

A escola é uma instituição criada, basicamente, para um fim específico: o de desenvolver uma parte muito importante da educação no sentido "lato" que é a disseminação do conhecimento sistematizado e acumulado historicamente; conhecimento esse imprescindível para a formação de um cidadão crítico, autônomo e participativo. No entanto, essa função precípua tem sido crescentemente obscurecida pelo fato de a sociedade, cada vez mais, "lavar as mãos" da educação no sentido lato e atribuir toda a responsabilidade de seu desenvolvimento à escola.

Lamentavelmente, por inúmeras razões que não cabe aqui ser aprofundado (veja, por exemplo, TANI $^{16}$ para maiores detalhes), o cenário assim criado permite inferir que a escola tem, implicitamente, aceitado essa ingrata responsabilidade. Pelo menos não se observa a escola se "rebelando" contra essa omissão gradativa e crescente da sociedade, cobrando-lhe o cumprimento da parte que lhe cabe. Ao contrário, por abraçar ou tendo que abraçar políticas educacionais elaboradas com base em teorias e propostas pedagógicas muitas vezes irreais e românticas, com forte viés ideológico e político-partidário, advindas da academia, a escola tem assumido discursos que se alinham com essa responsabilidade imputada, dando a impressão de que ela é capaz de cumpri-la. Obviamente, são discursos facilmente desmentidos pela prática, porquanto impossíveis de serem efetivados. 
Destarte, não há a remota possibilidade de a escola substituir a família, as entidades, instituiçōes e organizaçōes sociais no desenvolvimento da educação no sentido "lato". Aceitar essa responsabilidade é seguramente entregar-se à demagogia, ou seja, fazer de conta que educa sem de fato educar. Desafortunadamente, tudo indica que isso tem acontecido, estabelecendo-se um verdadeiro abismo entre o discurso e a prática, entre a promessa e o resultado. Oportuno lembrar que, ao fim e ao cabo, o não cumprimento do prometido, em qualquer atividade, implica sempre em aumento de desconfiança e descrédito.

Enquanto persistir a não diferenciação conceitual clara e inequívoca entre a educação no sentido "lato" e a educação escolarizada, fica difícil visualizar-se precisamente a função precípua da escola e, por conseguinte, os objetivos específicos de cada componente curricular. $\mathrm{O}$ fato de ainda não ter sido realizada essa importante e imprescindível diferenciação, permite especular que talvez ela possa ser, em certas circunstâncias, conveniente para ambas. Possibilita, por exemplo, o empurra-empurra de responsabilidades sem a necessidade de efetivamente assumi-las e dar satisfação dos resultados logrados.

Cria-se, dessa forma, uma situação esquizofrênica que evidencia uma cisão de identidade: a sociedade continua a achar que a escola é uma instituição necessária, tanto é que lhe confere a imensa responsabilidade da educação no sentido "lato" e, por outro lado, tornou-se lugar comum a avaliação social de que o sistema de ensino é uma instituição falida, pois cumpre muito mal a sua função. O que se presencia é um faz de conta generalizado e cinicamente compartilhado pela sociedade e pela escola.

É importante ressaltar, nesse momento da reflexão, que os objetivos da educação escolarizada não podem ser confundidos com as finalidades da educação no sentido "lato", mas devem a elas estar atrelados, por uma questão de pertença. Da mesma forma, os objetivos específicos da EFE não podem ser confundidos com as finalidades da educação escolarizada, mas devem a elas estar atrelados ${ }^{16}$.

Imersa neste cenário de persistente não diferenciação, a EFE continua com um problema fulcral, isto é, ela não tem ainda uma identidade claramente definida e, devido a sua ausência, tem encontrado grandes dificuldades em distinguir a sua função no processo de escolarização ${ }^{16}$. Por exemplo, quando se discute a relação da EFE com o esporte, mais especificamente o valor educativo do esporte ou a tentativa de sua legitimação como um fenômeno sociocultural de grande relevância para a educação, há sempre a dubiedade de se estar referindo à educação no sentido "lato" ou à educação escolarizada ${ }^{17}$.

O esporte também tem encontrado muitas dificuldades de concepção. Apesar de assumir cada vez mais um sentido plural (para uma compreensão mais abrangente e profunda, veja, por exemplo, BENTO ${ }^{18}$ ) que se traduz pela diversificação crescente de modalidades, de valores que servem de referência orientadora a seus praticantes, de motivos que levam à sua prática e de objetivos perseguidos pelos praticantes, quando se fala em esporte, a concepção subjacente é a de alto rendimento, muitas vezes a única.

Com o intuito de buscar uma concepção de esporte que seja capaz de abarcar toda essa pluralidade de sentidos, formas e significados, uma proposta de múltiplas perspectivas tem sido apresentada ${ }^{19-21}$. Ela parte do princípio de que o esporte é um patrimônio cultural da humanidade, ou seja, algo criado, transmitido e transformado através dos tempos, o que lhe confere uma natureza eminentemente dinâmica. E que, em virtude da ênfase em determinados aspectos (por exemplo, objetivo, população alvo, forma de trabalho, resultado esperado, entre outros), ele pode assumir características diferenciadas como, por exemplo, o esporte de alto rendimento e o esporte como conteúdo da EF, porém mantendo a mesma essência. Em outras palavras, o núcleo duro ("hard core") do esporte é o mesmo, atribuindo-lhe uma configuração única, mas com possibilidade de variação de acordo com o escalonamento nos "pesos" aplicados a alguns de seus aspectos.

Muitos fatores têm sido identificados como formadores e fortalecedores dessa concepção de esporte centrada no alto rendimento como a mídia, os interesses comerciais, o condicionamento social para a performance, entre outros, mas um que merece ser destacado nesse momento é a própria EF, tanto a escolar como a não-escolar. Elas influenciam e são influenciadas por essa concepção de esporte, esquecendo-se que o esporte de alto rendimento tem um caráter seletivo, restritivo e excludente. Portanto, quando a EFE trabalha com o esporte na perspectiva do alto rendimento, os problemas são inevitáveis, da mesma forma que, quando o esporte de alto rendimento é trabalhado na perspectiva do esporte como conteúdo da EF, dificilmente os seus objetivos serão alcançados ${ }^{16}$.

Procurando manter coerência com a finalidade da educação escolarizada, identificada como a disseminação do conhecimento sistematizado e acumulado historicamente, TANI $^{16}$ e TANI e MANOEL ${ }^{17}$ têm apresentado uma definição de EFE como uma disciplina curricular cuja meta é disseminar conhecimentos 
sistematizados e acumulados historicamente acerca do esporte, jogo, ginástica, exercício e dança, isto é, categorias de movimento que se caracterizam como fenômenos socioculturais e constituem uma parte importante do acervo cultural da humanidade denominada de cultura de movimento. Entenda-se como conhecimento sistematizado, o conjunto de conhecimentos acerca da estrutura, organização e significado dessas categorias de movimento.

A questão que surge diz respeito a como organizar o ensino desse patrimônio cultural de modo a garantir uma aprendizagem significativa para o aluno. TANI ${ }^{16}$, ${ }^{22-24}$ e TANi e MANOEL ${ }^{17}$ propõem que esses conhecimentos podem ser organizados em três focos de aprendizagens: aprendizagem do movimento, aprendizagem através do movimento e aprendizagem sobre o movimento. Ao promover essas três aprendizagens, a EFE estaria cumprindo a sua função como uma disciplina curricular no processo de escolarização.

Esses três focos de aprendizagem contemplam os vários tipos de aprendizagens apresentados por Coll $^{25}$, Coll et al. ${ }^{26}$ e ZaBALA ${ }^{27}$ para com o trato do conhecimento na escolarização, agrupado em três dimensōes: conceitual, procedimental e atitudinal. Nesse enquadramento, a aprendizagem do movimento corresponderia à aprendizagem dos conteúdos procedimentais, a aprendizagem através do movimento à aprendizagem de conteúdos atitudinais e a aprendizagem sobre o movimento à aprendizagem de conteúdos conceituais.

Mais especificamente, a dimensão procedimental refere-se ao saber fazer, a capacidade de mover-se numa variedade de situações, com gradativo aumento de complexidade, de maneira eficaz e harmoniosa. No que tange ao esporte, essa dimensão poderia referir-se, por exemplo, ao próprio saber jogar. A dimensão conceitual, também chamada de simbólica, refere-se à aquisição de um conjunto de conhecimentos sobre o movimento humano, desde os aspectos biológicos até os socioculturais. No esporte, ela está relacionada à aquisição de conhecimentos sobre as suas dimensões e implicações biológicas, psicológicas, sociais e culturais. A dimensão atitudinal relaciona-se a uma aprendizagem que utiliza o movimento como um meio para alcançar um fim, que não necessariamente se vincula a uma melhora na capacidade de se mover efetivamente; o movimento como meio para o aluno aprender sobre si e o meio ambiente social e cultural em que se insere. Aprender a respeitar os limites dos outros, as regras esportivas, assim como a desempenhar funçōes numa equipe são exemplos dessa dimensão que são inerentes à prática do esporte.

Como foi discutido, no cumprimento de suas funçōes no processo de escolarização a EFE deve promover esses três focos de aprendizagem. Cada foco tem suas metas, desafios e estratégias do ponto de vista didático-pedagógico. No entanto, consideradas as condições reais de desenvolvimento da EFE, a grande dificuldade se situa na aprendizagem do movimento. Quanto ao esporte, considerando a sua natureza sistêmica em que as habilidades motoras são hierarquicamente organizadas ${ }^{28}$, sabe-se que a aquisição dessas habilidades exige muita prática tanto no que se refere a tempo como dedicação ${ }^{29}$, condições essas raramente proporcionadas pela atual conjuntura da EFE. Conforme foi visto, ela é comumente oferecida duas vezes por semana, com aulas de 50 minutos, tempo reduzido em que o aluno fica efetivamente envolvido com a prática física, elevado número de alunos, precariedade de infraestrutura física e material e por um corpo docente de formação profissional deficiente. Desse modo pergunta-se: como adquirir habilidades motoras nessas condições? Seria essa mais uma proposta do faz de conta, do promete e não cumpre?

\section{As possibilidades do ensino de habilidades motoras esportivas na Educação Física Escolar}

Diante do quadro apresentado a respeito das reais condiçôes para o desenvolvimento das aulas de EFE e as exigências da aprendizagem do movimento, uma questão fundamental imediatamente emerge: há uma possibilidade real de se ensinar habilidades motoras esportivas na escola? Responder a essa questão não se configura como uma tarefa fácil, pois as origens de muitos dos problemas estão localizadas nas esferas mais profundas da política do sistema educacional e a superação desses problemas requer medidas de reestruturação que ultrapassam os limites das competências do professor de Educação Física. Todavia, existem ações que são possíveis de serem realizadas por esse especialista, com vistas a oferecer um ensino que não fique nos discursos demagógicos e nas promessas não cumpridas. 
Tendo como ponto de partida o entendimento de que o ensino do esporte na escola requer a aprendizagem de habilidades que assegurem ao aluno uma proficiência motora mínima, garantindo a sua inserção na cultura de movimento, a pergunta que necessita ser respondida é: o que é essencial a ser ensinado para que o aluno tenha sucesso na aprendizagem do movimento?

Uma possível solução para esse problema de compatibilizar a demanda de prática para assegurar a aprendizagem do movimento e as condiçôes reais oferecidas pela escola é proposta por TANI ${ }^{16,24}$, ao apresentar outra dimensão dessa mesma aprendizagem: o conhecimento sobre como melhorar a qualidade do movimento. Conhecer acerca de como melhorar a qualidade do movimento significa ser capaz de identificar os processos e procedimentos essenciais à aquisição de habilidades motoras. Dessa forma, a aquisição desse conhecimento na escola possibilitaria ao aluno a sua utilização em todas as oportunidades de prática fora dessa instituição, para melhorar a habilidade. Em outras palavras, em vez de procurar melhorar a habilidade motora nas aulas de EFE, o que se busca é a aquisição de conhecimentos sobre como melhorar essa habilidade. Essa premissa se coaduna legitimamente com duas assertivas da política educacional vigente, pelo menos quanto a princípios, quais sejam, de autonomia e de inclusão social pelo conhecimento.

A escola, segundo a UNESCO, estabelece como um de seus pilares o "aprender a aprender". Portanto, nas aulas de Educação Física, o professor deve procurar desenvolver no aluno a autonomia no processo de aquisição de habilidades motoras, o que implica acesso às informaçôes que se referem a descriçôes, procedimentos e dicas factuais que destaquem os aspectos essenciais para a sua aprendizagem ${ }^{30}$.

O processo de melhoria da qualidade do movimento ou a aquisição de habilidades motoras é o objeto de estudo do campo de investigação denominado Aprendizagem Motora, que tem um longo histórico de pesquisas realizadas. As dicas de aprendizagem são um dos temas investigados com estreita ligação com o presente desafio de buscar um saber relativo à melhoria da qualidade do movimento que pudesse ser ensinado na EFE, com vasto número de estudos realizados, sobretudo, como estratégias cognitivas para a canalização de atenção na aquisição de habilidades motoras (por exemplo, GALLAGHER et al. ${ }^{31}$; LADEWIG et al. ${ }^{32}$; Pasetto et al. ${ }^{33}$; Valentini $\&$ Toigo $^{34}$; MeDINA $\left.^{35}\right)$. Dicas verbais podem ser entendidas como uma forma de instrução verbal curta e direcionada para orientar o aprendiz aos elementos importantes da habilidade motora a ser executada ${ }^{34,36-38}$.

As dicas verbais desempenham duas funções primordiais: a) chamar a atenção para a informação relevante da habilidade; b) conduzir o aluno aos elementos do movimento da habilidade motora suscitada na tarefa, ou seja, preparar a ação para o movimento ${ }^{39}$. Para MAGILL ${ }^{39}$, a vantagem de utilização das dicas reside no fato de diminuir o número de instruçôes verbais, permitindo canalizar a atenção na percepção e no movimento da própria habilidade. As dicas verbais podem ser fornecidas com as seguintes intençôes: complementar a informação visual, uma vez que são usualmente fornecidas juntamente com a demonstração; chamar a atenção do aprendiz para partes relevantes da habilidade; e estimular a autoconversa - conversar com si próprio - sobre aspectos-chave da habilidade, durante a execução ${ }^{39}$. Ressalta-se que as dicas são específicas de cada tarefa, motivo pelo qual deixam de se enquadrar à categoria de aprendizagem sobre o movimento, apesar de estarem a ela relacionadas.

Com base nesses pressupostos, SiLVeira ${ }^{40}$ e Silveira et al. ${ }^{41}$ investigaram o efeito das dicas verbais como conteúdo de ensino na EFE, com alunos dos anos iniciais do Ensino Fundamental, com idade compreendida entre seis a oito anos, na aquisição de duas habilidades motoras manipulativas distintas quanto à demanda de processamento: rebater e driblar. As principais conclusões dos estudos foram: a) o efeito das dicas dependeu da sua relação com a especificidade da tarefa no que se refere à demanda de processamento; $b$ ) além de estarem atreladas à especificidade da tarefa, as dicas devem focar o elemento essencial da habilidade motora; c) a dica funcionou como um conhecimento que orientou os alunos sobre como melhorar a qualidade do movimento, ou seja, como aprender a habilidade motora, canalizando a atenção para o aspecto essencial da mesma; d) a dica se configurou como um saber escolar, cujo ensino contribuiu para o aluno construir um conhecimento significativo para a aprendizagem do movimento, que aprendido na EFE, pode ser utilizado em outras situações de prática da cultura de movimento para além do ambiente escolar, envolvendo esse tipo de habilidade.

Ademais, os dados obtidos nas duas avaliações quantitativas foram reiterados pelas avaliações qualitativas apuradas com base nos registros da docente em seu diário de bordo e nas sistematizaçôes dos alunos. Nesses registros, a docente relatou a implantação e o desenvolvimento das aulas experimentais com a utilização das dicas verbais, acompanhando e anotando os principais acontecimentos, efeitos e manifestaçôes 
dos alunos durante as atividades. Ressaltou, assim, a importância que as dicas tiveram para facilitar a aprendizagem e auxiliar no processo de ensino.

Nas sistematizaçôes dos alunos, as dicas verbais evidenciaram-se nos registros iconográficos e escritos acerca do aspecto mais importante aprendido nas aulas, sendo apontadas nos desenhos com reforço da linguagem escrita. Nesse aspecto, as dicas ganharam uma dimensão de conteúdos de ensino, pois levaram a uma melhora na aquisição das habilidades motoras, especialmente, nas situações em que mantiveram uma relação direta com a demanda de processamento e, dessa forma, passaram a configurar-se como um saber importante para serem aplicadas nos momentos de prática.

É importante reiterar que na perspectiva da promoção da aprendizagem do movimento, saber como melhorar a qualidade do movimento significou ser capaz de identificar os processos e procedimentos essenciais, necessários à aquisição de habilidades motoras. A aquisição desse conhecimento na escola visou, assim, possibilitar ao aluno a sua utilização em todas as oportunidades de prática fora da escola, para então melhorar a habilidade $e^{40,41}$.

Pesquisas sobre as dicas de aprendizagem como conteúdo de ensino da EFE ainda são incipientes, mas os resultados deste estudo são promissores e estimulam a realização de mais investigações. $\mathrm{Na}$ realidade, os professores, sobretudo os mais experientes, possuem um rico repertório de dicas que se mostram eficazes no ensino de habilidades motoras ao longo da sua carreira docente. $\mathrm{O}$ que se necessita é a sua sistematização à luz de conhecimentos acadêmico-científicos, para lhes dar robustez como conhecimento a ser devidamente incorporado no currículo escolar.

\section{Desafios para a concretização da possibilidade do ensino de habilidades motoras esportivas na Educação Física Escolar}

Conforme discutido, as dicas de aprendizagem como conhecimentos acerca do como melhorar a qualidade do movimento, ou seja, aquisição de habilidades motoras, podem se constituir importantes conteúdos de ensino da EFE. Elas possibilitam o ensino do esporte na escola em consonância com os objetivos da EFE, tendo em conta as condiçõos operacionais da escola. Evidentemente, não se tem aqui nenhuma intenção de subestimar a complexidade envolvida no ensino dessa disciplina na escola. Vários outros tipos de conhecimento devem ser buscados e investigados.

No entanto, as dicas de aprendizagem possuem uma peculiaridade que merece ser destacada: elas já são amplamente utilizadas, sobretudo pelos professores mais experientes, no ensino do esporte na escola. Esses professores possuem um rico repertório de dicas que tem se mostrado eficaz no ensino de habilidades motoras ao longo da sua carreira docente. Constituem importantes saberes docentes que devem ser socializados para a melhoria da EFE. Será um enorme desperdício se esses conhecimentos ficarem confinados ao repertório individual de cada professor e "desaparecerem" do cenário escolar com a sua aposentadoria. O que se necessita é a sua sistematização à luz de conhecimentos acadêmico-científicos, para lhes dar robustez como conteúdo de ensino a ser devidamente incorporado no currículo escolar.

A sistematização dessas dicas envolve a elaboração de uma base teórica acerca dos seus mecanismos e processos subjacentes e a sua verificação experimental em ambientes escolares. Entende-se que transformar esse empreendimento em uma linha de pesquisa na academia reveste-se não apenas de interesses pedagógicos, mas revela também um posicionamento em relação à própria caracterização da $\mathrm{EF}$ como uma área de conhecimento. Como se sabe, a EF ainda não definiu claramente a sua identidade acadêmica, permanecendo na ambiguidade entre uma área de natureza acadêmica ou profissionalizante (maiores detalhes em TANI ${ }^{19,42,43}$ ). Essa linha de pesquisa teria como meta buscar subsídios para a intervenção, ou seja, produzir conhecimentos de aplicação prática.

O desenvolvimento dessa linha de pesquisa envolveria, inicialmente, um levantamento amplo de dicas junto aos professores, dicas que se mostram eficazes no ensino de habilidades motoras esportivas. Alguns exemplos já conhecidos, para efeitos de ilustração são: queixo no peito no ensino da cambalhota, empurrar a bola em vez de bater na bola no ensino do rebater no tênis, desenhar um " $S$ " no ensino da braçada do nado "crawl", "dedo do pé até calcanhar" no ensino do galopar, entre outros.

Uma vez organizadas as dicas que efetivamente ajudam os alunos no processo de aprendizagem deve-se buscar possíveis explicações acerca dos seus efeitos à luz de conhecimentos acadêmicocientíficos, considerando importantes variáveis como tipo de habilidade (aberta/fechada; discreta/ 
seriada/contínua; lenta/balística, etc.), fase da aprendizagem em que os alunos se encontram (fase cognitiva/associativa/autônoma), o estágio de desenvolvimento motor dos alunos (primeira infância, segunda infância, adolescência) e suas possíveis combinaçôes.

Finalmente envolveria a transformação dessas possíveis explicações em hipóteses de estudo para serem devidamente testadas em situações concretas

\section{Considerações finais}

O presente ensaio teve como pano de fundo um alerta e um questionamento. $\mathrm{O}$ alerta foi em relação ao papel da escola e a sua contribuição para o desenvolvimento do esporte de alto rendimento. $\mathrm{O}$ papel da escola é, assumindo o esporte como patrimônio cultural da humanidade, inserir o aluno nessa cultura mediante a disseminação do conhecimento sistematizado e acumulado historicamente a seu respeito. Em outras palavras, a escola é uma instituição privilegiada para promover a aculturação esportiva (disseminação de conhecimentos, atitudes, valores e habilidades) para que crianças e jovens possam se tornar cidadãos conhecedores do seu valor intrínseco, seja biológico, psicológico, social ou cultural e capazes de fazer da sua prática regular um importante fator de promoção do bem estar ao longo de suas vidas ${ }^{16}$.

Portanto, a contribuição da escola para o desenvolvimento do esporte de alto rendimento é apenas indireta, no sentido de que, se ela cumprir bem o seu papel educacional, amplia-se o número de praticantes sensibilizados pelos seus valores intrínsecos. Consequentemente, crescem as possibilidades de aumentar o contingente de pessoas com potencial para participar do esporte de alto rendimento. $\mathrm{O}$ desenvolvimento desse potencial deve ocorrer em instituições especificamente constituídas para esse fim.

Partindo-se do entendimento de que a escola deve disseminar o esporte, porque ele se constitui num patrimônio cultural da humanidade e isto pode ser visto como uma condição necessária para favorecer o desenvolvimento do esporte de alto rendimento, o questionamento recai sobre as reais possibilidades de se ensinar o esporte na escola em consonância com do mundo real, ou seja, nas aulas de EFE. Evidentemente, esse tipo de pesquisa envolveria a participação ativa e integrada de professores que atuam nas escolas e pesquisadores que trabalham na academia. Caracterizaria, portanto, uma linha de pesquisa possível de ser implementada no contexto escolar, integrando as áreas de Comportamento Motor e Pedagogia do Movimento à escola e transformando o professor da escola em pesquisador.

os objetivos da EFE, tendo em conta as condições em que ela se encontra.

O ensino do esporte na escola requer a aprendizagem de habilidades que assegurem ao aluno uma proficiência motora mínima, garantindo a sua inserção nessa cultura de movimento, de forma que a questão central é saber o que é essencial a ser ensinado para que o aluno tenha sucesso na aprendizagem dessas habilidades. Em outras palavras, compatibilizar a demanda de prática para assegurar a aprendizagem e as condições reais oferecidas pela escola.

Uma possível resposta a essa indagação foi trabalhar uma dimensão da aprendizagem do movimento que se refere aos conhecimentos sobre como melhorar a qualidade do movimento. Conhecer acerca de como melhorar a qualidade do movimento significa ser capaz de identificar os processos e procedimentos essenciais à aquisição de habilidades motoras. Um dos conhecimentos dessa natureza, privilegiado no presente ensaio, foi as dicas de aprendizagem que têm uma longa história de estudos na área de Aprendizagem Motora, como de aplicação prática na intervenção profissional.

Como os professores, sobretudo os mais experientes, possuem um rico repertório de dicas que se mostram eficazes no ensino de habilidades motoras ao longo da sua carreira docente, o que se requer é a sua sistematização à luz de conhecimentos acadêmicocientíficos. Uma linha de pesquisa com a participação integrada de professores e acadêmicos para dar corpo a esse desafio parece ser altamente necessária e promissora. Ademais, trata-se de uma ação concreta de aproximar e integrar a universidade e a escola. 


\begin{abstract}
The teaching of sport motor skills in the school and the high performance sport: discourse, reality and possibilities

The amplification of mass sport practice starting from school physical education has been suggested as an effective way to transform Brazil in a powerful high performance sport country. The objective of this essay is to analyze and reflect on discourse, reality and possibilities of teaching sport in the schools having as a background the relationship between school physical education and high performance sport. In other words, to carry out a critical analysis to qualify the link school-high performance sport in order to make clear the social role of the school and its eventual contribution to the formation of athletes, and to discuss the real possibilities to teach sport in the schools, particularly motor skills, considering the conditions in which they now are.
\end{abstract}

KEY WORDS: School physical education; Sport; Teaching of motor skills.

\title{
Referências
}

1. Tani G, Meira Junior CM, Oliveira JA, Côrrea UC. O day after olímpico e a universidade. Rev Educ Fís/UEM. 2009;20:485-97.

2. Brasil. Lei n. 9394 de 20 de dezembro de 1996. Lei de Diretrizes e Bases da Educação Nacional. Diário Oficial da União, Brasília (DF). 199623 dez.; Seção 1:27833.

3. São Paulo (Estado). Secretaria da Educação. Dispõe sobre as sessões de Atividades Curriculares Desportivas - ACD, nas unidades escolares da rede pública estadual. Resolução n. 14, 2 fevereiro 2010. Diário Oficial do Estado de São Paulo, São Paulo (SP). 20103 fev.; Poder Executivo, Secão 1:18.

4. São Paulo (Estado). Decreto n. 58.986 de 21 de março de 2013. Institui os Jogos Escolares do Estado de São Paulo e dá providências correlatas. Diário Oficial do Estado de São Paulo, São Paulo (SP). 201322 mar.; Poder Executivo, Secão 1:1.

5. São Paulo (Estado). Resolução Conjunta SE/SELJ/SDPcD/SDECT 1, de 22 de março de 2013. Diário Oficial do Estado de São Paulo, São Paulo (SP). 201323 mar.; Poder Executivo, Secão 1:41.

6. São Paulo (Estado). Secretaria da Educação. Currículo do Estado de São Paulo: linguagens, códigos e suas tecnologias. São Paulo: Secretaria da Educação; 2010.

7. São Paulo (Estado). Secretaria da Educação. Estabelece diretrizes para a organização curricular do ensino fundamental e do ensino médio nas escolas estaduais. Resolução n. 81, 16 dezembro 2011. Diário Oficial do Estado de São Paulo, São Paulo (SP). 201117 dez.; Poder Executivo, Secão 1:28.

8. Duarte J, Gargiulo C, Moreno M. School infrastructure and learning in Latin American elementary education: an analysis based on the SERCE. [s.l.]: Inter-American Development Bank, Education Division (SCL/EDU); 2011.

9. Bogler R. Two profiles of schoolteachers: a discriminant analysis of job satisfaction. Teaching and Teacher Education. 2002;18:665-73.

10. Both J, Nascimento JV, Lemos CAF, et al. Quality of life at work by physical education teachers. Rev Bras Cineantropom Desempenho Hum. 2006;8:45-52.

11. Gomes MA, Borges LJ, Nascimento JV. Ciclos de desenvolvimento profissional e a qualidade de vida de professores de educação física da região sudoeste da Bahia. Rev Bras Ed Fís Esporte Lazer Dança. 2007;2:104-11.

12. Folle A, Lemos CAF, Nascimento JV, Both J, Farias GO. Career in public teaching and degree of life quality in physical education teaching. Motriz: Rev Educ Fís. 2008;14:210-21.

13. Tokuyochi JH, Bigotti S, Antunes FH, et al. Retrato dos professores de educação física das escolas estaduais do Estado de São Paulo. Motriz: Rev Educ Fís. 2009;14:418-28.

14. Guedes JERP, Guedes DP. Características dos programas de educação física escolar. Rev Paul Educ Fís. 1997;11:49-62.

15. Correia WR. Educação física escolar e o esporte no Brasil: entre o insólito e o impertinente. In: Bento JO, Tani G, Prista AMM, organizadores. Desporto e educação física em português. Porto: Universidade do Porto; 2010. p.100-7.

16. Tani G. Desporto e escola: que diálogo ainda é possível? In: Bento JO, Constantino JM, coordenadores. Em defesa do desporto: mutações e valores em conflito Coimbra: Almedina; 2007. p.269-87.

516 • Rev Bras Educ Fís Esporte, (São Paulo) 2013 Jul-Set; 27(3):507-18 
17. Tani G, Manoel EJ. Esporte, educação física e educação física escolar. In: Gaya AC, Marques AT, Tani G, organizadores. Desporto para crianças e jovens: razôes e finalidades Porto Alegre: Universidade Federal do Rio Grande do Sul; 2004. p.113-41.

18. Bento JO. Pedagogia do desporto: definições, conceitos e orientações. In: Tani G, Bento JO, Petersen RDS, editores. Pedagogia do Desporto. Rio de Janeiro: Guanabara Koogan; 2006. p.1-97.

19. Tani G. Cinesiologia, educação física e esporte: ordem emanante do caos na estrutura acadêmica. Motus Corporis. 1996;3:9-50.

20. Tani G. Esporte e processos pedagógicos. In: Moreira WW, Simōes R, organizadores. Fenômeno esportivo no início de um novo milênio. Piracicaba: Universidade Metodista de Piracicaba; 2000. p.85-90.

21. Tani G. Esporte, educação e qualidade de vida. In: Moreira WW, Simões R, organizadores. Esporte como fator de qualidade de vida. Piracicaba: Universidade Metodista de Piracicaba; 2002. p.103-16.

22. Tani G. Perspectivas para a educação física escolar. Rev Paul Educ Fís. 1991;5:61-9.

23. Tani G. Educação física escolar no Brasil: seu desenvolvimento, problemas e propostas. II Seminário Brasileiro de Pedagogia do Esporte; 1998; Santa Maria, RS. Santa Maria: Universidade Federal de Santa Maria; 1998. p.120-7.

24. Tani G. Abordagem desenvolvimentista: 20 anos depois. Rev Educ Fís/UEM. 2008;19:313-31.

25. Coll C. Aprendizagem escolar e construção do conhecimento. Porto Alegre: Artes Médicas; 1994.

26. Coll C, Pozo JI, Sarabia B, Valls E. Os conteúdos na reforma: ensino e aprendizagem de conceitos, procedimentos e atitudes. Porto Alegre: Artes Médicas; 2000.

27. Zabala A. A prática educativa: como ensinar. Porto Alegre: Artes Médicas; 1998.

28. Corrêa UC, Tani G. Esportes coletivos: alguns desafios quando abordados sob uma visão sistêmica. In: De Rose Júnior D, editor. Modalidades esportivas coletivas. Rio de Janeiro: Guanabara Koogan; 2006. p.15-23.

29. Ericsson KA, Krampe RT, Tesch-Römer C. The role of deliberate practice in the acquisition of expert performance. Psychol Rev. 1993;100:363-406.

30. Tani G, Freudenheim AM, Ugrinowitsch C, et al. Apostila do Curso "Educação Física, Vida e Movimento". São Paulo: Secretaria de Estado da Educação, Coordenadoria de Estudos e Normas Pedagógicas; 2006.

31. Gallagher JD, French KE, Thomas K, Thomas JR. Expertise in youth sport: the relationship between knowledge and skill. In: Smoll FL, Smith RE, editors. Children and youth in sport: a biopsychosocial perspective. Indianapolis: Brown \& Benchmark; 1993. p.338-58.

32. Ladewig I, Cidade RE, Ladewig MJ. Dicas de aprendizagem visando aprimorar a atenção seletiva em crianças. In Teixeira LA, editor. Avanços em comportamento motor. São Paulo: Movimento; 2001. p.166-97.

33. Pasetto SC, Araújo PF, Corrêa UC. Efeitos de dicas visuais na aprendizagem do nado crawl para alunos surdos. Rev Port Ciênc Desporto. 2006;6:281-93.

34. Valentini NC, Toigo AM. Ensinando educação física nas séries iniciais: desafios e estratégias. Canoas: Unilasalle; 2004.

35. Medina J. Dicas de aprendizagem na aquisição do rolamento peixe por crianças com transtorno do desenvolvimento da coordenação [dissertação]. Curitiba: Universidade Federal do Paraná; 2007.

36. Landin D. The role of verbal cues in skill learning. Quest. 1994;46:299-313.

37. Freudenheim AM, Iwamizu JS, Santos S. Da pesquisa sobre instrução à intervenção profissional. In: Corrêa UC, organizador. Pesquisa em comportamento motor: a intervenção profissional em perspectiva. São Paulo: Universidade de São Paulo; 2008. p.231-9.

38. Schmidt RA, Wrisberg CA. Aprendizagem e performance motora: uma abordagem da aprendizagem baseada na situação. 4a ed. Porto Alegre: Artmed; 2010.

39. Magill RA. Aprendizagem motora: conceitos e aplicações. 5a ed. São Paulo: Edgard Blücher; 2000.

40. Silveira SR. Aquisição de habilidades motoras na educação física escolar: um estudo das dicas de aprendizagem como conteúdo de ensino [tese]. São Paulo: Universidade de São Paulo; 2013.

41. Silveira SR, Basso L, Freudenheim AM, Corrêa UC, Ferreira MG, Tani G. Aquisição da habilidade motora rebater na educação física escolar: um estudo das dicas de aprendizagem como conteúdo de ensino. Rev Bras Educ Fís Esporte. 2013;27:149-57.

42. Tani G. 20 anos de ciências do esporte: um transatlântico sem rumo? Rev Bras Ciênc Esporte. 1998;(n. esp.):19-31.

43. Tani G. Área de conhecimento e intervenção profissional. In: Corrêa UC, organizador. Pesquisa em comportamento motor: a intervenção profissional em perspectiva. São Paulo: Universidade de São Paulo; 2008. p.14-25.

44. Tani G. A educação física e o esporte no contexto da universidade. Rev Bras Educ Fís Esporte. 2011;25(n.esp.):117-26. 
Tani G, et al.

\begin{tabular}{r|r} 
ENDEREÇo & \\
Go Tani & \\
Escola de Educação Física e Esporte - USP & Recebido para publicação: 01/07/2013 \\
Av. Prof. Mello Moraes, 65 & Aceito: 12/07/2013 \\
05508-030 - São Paulo - SP - BRASIL & \\
e-mail: gotani@usp.br/pedagogi@usp.br &
\end{tabular}

518 • Rev Bras Educ Fís Esporte, (São Paulo) 2013 Jul-Set; 27(3):507-18 